Aerospace companies reports export orders worth more than $£ 50$ million (for comparison, the British motor industry exported goods worth just over $£ 58$ million in the same period). Orders were even healthier, and are probably worth $£ 500$ million so far this year. The director of the SBAC says that the past few months have marked a "vital turning point" in the industry's fortunes.

Even the European airbus seems to have had new life breathed into it, after months in which only vigorous artificial respiration by $\mathrm{Mr}$ John Stonehouse of the British Ministry of Technology kept hopes alive. The situation has changed because of a new determination on behalf of the German Government (prodded by the recommendations of a special parliamentary committee) that Lufthansa, the West German airline, should buy the A 300 . Lufthansa has been playing a waiting game, and has hinted at times that the A 300 is not the sort of aircraft it wants. But airbus enthusiasts now say that this merely represented a certain independence of thought which Lufthansa enjoys because it is in part privately owned. Now that the German Government is becoming involved, it is likely that Lufthansa will be persuaded to take as many as 20 airbuses. If British European Airways agrees to take 25, and Air France and Air Inter, the French airlines, can manage to order 30 between them, the airbus will be home and dry. An initial order for 75, as $\mathrm{Mr}$ Stonehouse emphasized at the Hanover Fair last week, is an absolute prerequisite for a decision to proceed.

If this hurdle is cleared, the international consortium could be given the go-ahead by July this year. According to Hawker-Siddeley, one of the British companies involved, metal could be cut by the end of the year. The design now agreed differs slightly from the original; market research by the airlines showed that passengers would prefer full dining service, and providing this inevitably leads to an increase in weight. In order to keep within the cost targets originally set, the fuselage of the aircraft has been reduced in diameter by 18 inches, which gives aerodynamic and cost advantages. The result, however, is that instead of nine to ten seats abreast, airbus passengers will be sitting eight to nine abreast, and in order to fit the same number in, the "pitch" between the rows of seats has been reduced from 34 to 32 inches. Though better fed, passengers will therefore be more cramped. A 32 inch pitch is distinctly tight-most modern airliners, including Boeing 707 and 727, Trident, BAC 111 and the like, provide 34 inches between rows. As tall passengers know, even this is not a very generous allowance. Fortunately the routes the airbus is designed to fly are short enough not to make the discomfort matter so much.

\section{On the Track of Voiceprints}

THERE are ominous signs that the appearance of voiceprints as a legal method of identification may precede any scientifically acceptable evidence of their validity for this purpose. Several makes of voiceprint machine are already being marketed on both sides of the Atlantic with the claim that voiceprints are as good as fingerprints, or nearly so, for identifying individuals. At least three police forces in Britain, and doubtless more in the United States, have been persuaded to invest in the instruments.
Sound spectrographs are machines which analyse sounds in terms of their frequencies and amplitudes and produce graphical displays to show the variation of these quantities with time. Conventional machines, of the type first developed in 1940 by the Bell Telephone Laboratories, produce plots of frequency against time, the amplitude being shown by the thickness of the line. Such displays are known as sound spectrograms. A different form of display in which amplitude intervals are represented by contour lines has been developed by Mr L. G. Kersta, who coined for it the term "voiceprint" by deliberate analogy with fingerprint.

To the unpractised eye, voiceprints present a more meaningful picture than do conventional sound spectrograms, but they probably contain less rather than more information. In 1962, Mr Kersta announced that voiceprints could be used to identify individuals (Nature, 196, 1253). In support of this contention he described experiments in which eight girl students given a week's training were asked to match voiceprints of single sounds produced by the same speaker. 'The girls performed better with voiceprints than sound spectrograms and, in 2,000 decisions with voiceprints, made only one per cent of errors.

Mr Kersta pointed out in the same article that there were several problems to be settled before voiceprints could be assumed to identify individuals reliably. Not enough voiceprints have been sampled to know whether a human voice can be counted unique, nor is it certain that any uniqueness there may in fact be will survive the changing of the voice with age or attempts to disguise it. "All these questions," $\mathrm{Mr}$ Kersta said, "must be answered by substantiating experimental evidence. It is my opinion, however, that identifiable uniqueness does exist in each voice and that masking, disguising or distorting the voice will not defeat identification if the speech is intelligible."

In the six years since these words were written, the "substantiating experimental evidence" for which $\mathrm{Mr}$ Kersta judiciously called has not been readily apparent. Indeed, there seems to be no body of academically acceptable evidence to refute the objections originally raised by Mr Kersta or to support his opinion that voiceprints would provide a unique and foolproof method of identification. But this has not, as it ought to have, prevented manufacturers from marketing machines designed for police use and claiming that voiceprints are unique. "Voiceprint identification," says one manufacturer's catalogue, "is based on the combination of physical characteristics unique to each individual's vocal cavities." It is also implied that voiceprints can be satisfactorily interpreted by anyone with a brief training in their use.

The point has now been reached where voiceprints have been admitted as evidence by several courts in the United States and as corroborative evidence by a court in Britain. In all these cases, the voiceprints have been interpreted by experts, not by the police, and in the latter case at least the expert consulted was at pains to emphasize that the voiceprints provided merely an impression, not a proof, of identity.

In Britain at least it is not known what use the police forces intend to make of the voiceprint spectrographs they have purchased-one possible application is to test the identity and credibility of hoaxing telephone calls - nor on what evidence they intend to justify the validity of voiceprints. There seems to be no published 
evidence which would command academic approval, and as far as is known no government agency has been asked by the police to assess the spectrographs. On the telephone, the manufacturer declined to say which police forces had bought the spectrographs.

Phoneticians both in Britain and the United States are considerably alarmed by the attempts to introduce voiceprints as legal evidence. It is well known that the voice changes with age and with emotion, and can be disguised and mimicked. Each such source of variability produces corresponding changes in spectrograms and voiceprint changes which are more than likely to conceal the posited but still unproved uniqueness of the individual voice. The circumstances in which recordings for legal use are likely to be made, for example by telephone tapping, are notorious for distorting sound; comparison of a voiceprint made from such a recording with one taken directly from the suspect presents yet further difficulties of interpretation.

Mr Kersta's Nature article of 1962 remains, as far as is known, the most serious attempt to evaluate voiceprints. Since then he has apparently been less cautious in his claims. Perhaps because of the lack of published material, there seems to have been a disinclination in academic circles to take these claims seriously. A thorough assessment is likely to be a lengthy and somewhat unrewarding task, which may be one reason why the several experiments which militate against the claims have been conducted on an informal basis and remain unpublished.

\section{How Much Electricity?}

THE electricity generating industry in Britain has just made an odd decision-that $£ 16$ million can be saved from the investment programmes because of revisions in the trend of demand for electricity. This reduction is very small when seen against the total investment programme of the electricity generating boards, and in the ordinary course of events would hardly be worthy of comment. But the $£ 16$ million cut has come on top of cuts of $£ 17$ million made in the public expenditure crisis of December 1967, and at a time when the Central Electricity Generating Board is talking cheerfully of a return to traditional growth rates for electricity consumption, after several years of relative stagnation. Those suspicious of the Ministry of Power's estimates have thus been given further ground for doubt; it looks as if the ministry's estimates are simply adjusted to fit short term capital shortages.

The industry's record in estimating demand over the past ten years has been woeful. First, in the early fifties, the estimates were pitched far too low, a mistake which led directly to the power cuts of 1962-63. The estimate made in 1953 for demand in 1959-60 was no less than 10 per cent too low. From this, the industry went to the other extreme, urged on by the "expansionist" phase in economic management between 1964 and 1966-the time of the National Plan. The estimates made in the early $60 \mathrm{~s}$ were as bad as those of the $50 \mathrm{~s}$, though in the other direction; the only thing that saved the CEGB from a vast over-capacity was its inability to get power stations finished on time. Thus in 1968-69, the plant actually in commission $(46,400$ MW) would have fallen 7 per cent short of demand if the original estimates had been right. In fact, it represents an over-capacity of about 25 per cent. The past two years, since the abandonment of the plan, have seen reductions in the estimates. Last year, for example, the Electricity Council said that demand in 1972-73 would be $54,000 \mathrm{MW}$; this year it says that this demand will not be reached until 1973-74, and that demand in $1972-73$ will be only $50,600 \mathrm{MW}$. The average rate of growth of consumption between now and then will be $7 \cdot 2$ per cent a year; last year the council thought it would be $7 \cdot 3$ per cent.

There seems to be no particular reason for believing that this latest estimate will be any more reliable than its predecessors. But it does seem to reflect a lack of optimism in the effects of devaluation which might not be endorsed by the Government. In any case, it is a pity to postpone investments now which in the long term are the only way of reducing electricity charges to the consumer. If the industry has too many power stations in 1974 , it can at least scrap some of the old and inefficient ones; but if it has too few, it will look very silly indeed.

Meanwhile, the Electricity Council is looking for a new chairman. Sir Ronald Edwards, chairman of the council since 1962, announced last week that he would resign at the end of October, to become chairman and chief executive of the Beecham Group. The job at present pays $£ 12,500$ a year, but may have to be increased to attract the right applicant. It is also possible that any new appointment would be tied in with a plan to reorganize the electricity generating industry.

\section{New Ways to Make Steel}

THe British Iron and Steel Research Association seems to have managed the transition from private to public status without disruption. Since the British steel industry was nationalized on July 28, 1967, BISRA has had two roles to fill-as the inter-group laboratories of the British Steel Corporation and as a research association continuing to serve the companies still in private hands. So far, the change is not apparent, at least in the work which is discussed in the annual report of BISRA, most of which is along familiar lines.

During the year trials began on a new steelmaking process, designed to make steel from cold charges. This uses an atomized spray of oil burning in oxygen as the only source of heat for steelmaking. Most of the development work is being carried on at Dorman Long (Steel) Ltd, where an 80 tonne vessel has been commissioned. The lessons learned with a small half tonne vessel are being applied to the larger scale development, and the intention is to devise the best possible working conditions and then to compare the process with the electric arc process. The charge is a mixture of scrap and pig-iron, and the burners use oil and oxygen in different proportions to produce different final steel compositions. Two kinds of burner have been used; a Dorman Long burner in which the oil is atomized with steam, and a BISRA design in which the atomization is carried out by what are called "swirl inserts". So far BISRA is not saying how well the process works.

Another major development in steelmaking, the spray process, has now passed out of BISRA's hands and is the responsibility of a wholly owned subsidiary, 